\title{
Dialética da ocupação de áreas de várzea em Belém e propostas de drenagem compreensiva
}

\section{Dialectics of occupation in lowland areas of Belém and proposals for comprehensive drainage}

Nállyton Tiago de Sales Braga - Mestre em Arquitetura e Urbanismo, pela Universidade Federal do Pará (UFPA). E-mail: nallyton.tiago@gmail.com

Mariana dos Santos Gouveia - Graduada em Arquitetura e Urbanismo, pela Universidade da Amazônia (UNAMA). E-mail: mgouveia753@gmail.com

\section{Resumo}

O processo de urbanização do bairro do Reduto, em Belém, foi caracterizado por mudanças socioestruturais intensas, que tiveram como resultado a transformação de uma área de várzea, inicialmente ocupada por assentamentos precários e famílias em situação de extrema vulnerabilidade social, em núcleo de elevada especulação imobiliária e condomínios de luxo. Este estudo tem como objetivo discutir a dinâmica de ocupação da baixada, bem como as consequências de tais processos sobre a drenagem de águas superficiais, a partir da análise da evolução dos padrões de uso e ocupação do solo e redução de coberturas naturais vegetadas, correlacionadas ao surgimento de focos de inundações e alagamentos. O texto aborda, como proposta, a incorporação de sistemas de drenagem compreensíveis, em especial a tecnologia de pavimentos de concreto permeável, como uma alternativa viável para o enfrentamento aos problemas de drenagem urbana na capital paraense.

\section{Palavra-chave}

Urbanização. Área de Baixada. Drenagem. Tecnologias Compreensivas. Concreto Permeável.

\begin{abstract}
The urbanization process of the district of Reduto, in Belém, was characterized by intense socio-structural changes, which resulted in the transformation of a lowland area, initially occupied by precarious settlements and families of extreme social vulnerability, in a nucleus of high real estate speculation and luxury condominiums. This study aims to discuss the dynamics of occupation of this lowland area, as well as the consequences of such processes on the drainage of surface water, from the analysis of the evolution of the patterns of use and occupation of the soil and reduction of natural coverings vegetated areas, correlated to the appearance of floods. The text addresses, as a proposal, the incorporation of comprehensible drainage systems, especially the technology of pervious concrete pavements, as a viable alternative for facing urban drainage problems in the capital of Pará.
\end{abstract}

\section{Keywords}

Urbanization. Lowland Region. Drainage. Comprehensive Technologies. Pervious Concrete. 


\section{INTRODUÇÃO}

O avanço urbano ocorre, em sua maioria, a partir de processos desorganizados e sem planejamento adequado para o desenvolvimento de sistemas que tenham capacidade estrutural para atender às demandas e necessidades sociais de habitação e saneamento ambiental. Isso, por sua vez, acaba interferindo de modo decisivo sobre a qualidade de vida das populações urbanas e sua capacidade de adaptação e reorganização diante de processos contínuos - de mudanças às quais o sistema urbano é submetido.

Os sistemas de drenagem e distribuição de águas superficiais apresentam, nesse contexto, relevante impacto sobre a qualidade de vida das pessoas, por estarem diretamente relacionados à ocorrência de desastres ambientais associados a inundações, alagamentos, desmoronamentos, bem como à propagação de doenças de veiculação hídrica, tais como a leptospirose e a febre tifoide (SANTOS, 2017). Os mecanismos de macro e microdrenagem tradicionalmente empregados por gestores públicos são, muitas vezes, importados de sistemas que apresentaram desempenho adequado para as solicitações ambientais de outras regiões, e são aplicados a realidades completamente distintas daquelas para as quais foram inicialmente imaginados, desprovidos de estudos prévios de compatibilização ambiental com as respectivas necessidades locais da população e do sistema ambiental como um todo.

Se, por um lado, a gestão pública apresenta baixa eficácia no desenvolvimento de sistemas urbanos mais sustentáveis e adaptáveis às particularidades e variações climáticas e ambientais locais, por outro, existem movimentos globais para a obtenção de soluções eficientes, resilientes e sustentáveis. Assim, destaca-se o plano de ações integradas criado pelo governo chinês no ano de 2012, que tem como objetivo o incentivo a estudos e projetos para criação de tecnologias de drenagem inovadoras e sustentáveis, a partir das quais as cidades possam se tornar flexíveis às mudanças climáticas e ao avanço urbano (DONG; GUO; ZENG, 2017).

Nesse contexto, observam-se, nos bairros do município de Belém, situações de avanço urbano e implantação de infraestruturas de drenagem não inclusivas e que não corresponderam, no decorrer das décadas, às respectivas demandas locais e sociais de desenvolvimento de políticas públicas, interferindo continuamente sobre a manutenção da qualidade de vida da população.

Toma-se, como objeto específico da análise, a área hoje correspondente ao Reduto, pois, conforme abordam Costa e Lobo (2012), esse bairro pode ser caracterizado como um espaço que passou por profundas e aceleradas alterações 
socioespaciais promovidas por intervenções do poder público e da especulação imobiliária. Desse modo, transitou da condição de área predominantemente permeada por assentamentos precários pertencentes a comunidades vulneráveis para um local ocupado por habitações verticais de elevado padrão econômico e um "corredor de comércio e serviços de âmbito metropolitano" (COSTA; LOBO, 2012, p. 142), destacando-se serviços e mercados direcionados a públicos de maior poder aquisitivo.

\section{A DINÂMICA DE OCUPAÇÃO DAS ÁREAS DE BAIXADA EM BELÉM}

No contexto da evolução urbana e industrial da região amazônica, observase que os processos contínuos de urbanização e metropolização do município de Belém são resultado da interação de fatores políticos, sociais e econômicos diferentes daqueles que impulsionaram o avanço urbano dos municípios de entorno dessa metrópole, ou mesmo a urbanização de outros polos industriais e econômicos regionais, que foram submetidos a contextos de ocupação e desenvolvimento de paradigmas produtivos e reorganização socioespacial distintos daqueles identificados na capital paraense.

Entendem-se tais diferenças como consequência de processos de urbanização regimentados por contextos e necessidades díspares, baseados principalmente na região amazônica brasileira - na regionalização associada a polos de crescimento locais, criados com a finalidade de viabilizar Planos Econômicos Desenvolvimentistas e interesses corporativos, aqueles geralmente engendrados a partir de modelos de ordenamento territorial e ocupação da Amazônia, e esses associados ao extrativismo e à exploração de recursos naturais locais.

A dinâmica de ocupação e desenvolvimento de aglomerados urbanos nos bairros da capital paraense, por sua vez, foi influenciada por modelos urbanísticos e paradigmas tecnológicos e industriais em território nacional e regional, notadamente em três períodos distintos: de 1850 a 1920, quando se observou o boom econômico do ciclo da borracha na Amazônia, o crescimento de financiamento para sistemas produtivos locais, a intensificação e interação de núcleos de povoamento em nível estadual e regional; de 1920 a 1960, momento em que se destaca o impacto da perda de mercado sobre a formação da rede urbana municipal e a estagnação econômica; e a partir de 1960, quando se deu a reorganização da rede urbana municipal e o desenvolvimento de projetos para criação e modernização de sistemas de saneamento básico e canalização de córregos, igarapés e leitos de rios (CORRÊEA, 2006). 
O crescimento da cidade de Belém e as mudanças em sua dinâmica territorial e social foram influenciados, ainda, pela ação conjunta de atores econômicos, imobiliários e de segregação espacial planejada, em que se destaca a ocupação imobiliária de áreas centrais para a produção de empreendimentos de elevado apelo econômico - mesmo aquelas localizadas em áreas de várzea, comumente povoadas por assentamentos precários, mal supridas de infraestrutura de saneamento básico, e consequentemente habitadas por populações em situação de maior vulnerabilidade econômica e fragilidade social (TRINDADE JÚNIOR, 1999; PONTE; BRANDÃO, 2014).

\section{BAIRRO DO REDUTO}

Costa e Lobo (2012) apontam para contextualização e caracterização histórica do bairro do Reduto, que a instalação de uma fábrica de solas na foz do igarapé das águas, em 1852 (que seria posteriormente canalizado e rebatizado como Canal do Reduto) permitiu a urbanização de suas margens, evitando, desse modo, os constantes alagamentos do bairro de entorno, associados às chuvas intensas e à proximidade do igarapé. Além disso, a construção de uma doca, em 1859, para facilitar a comercialização dos produtos trazidos pelas vias fluviais, também funcionou como impulsionador da urbanização local.

Em seu estudo, Penteado (1968) aborda que a prosperidade econômica regional associada às exportações, notadamente da borracha, possibilitou a ampliação do Porto de Belém pela companhia Port of Pará, resultando no fechamento e aterramento da doca localizada no Reduto, em 1910 (Figura 1).

Desse modo, o bairro passou por um período de desvalorização imobiliária e abandono, sendo somente ocupado mais enfaticamente a partir de 1940, principalmente por operários das fábricas que se instalaram naquela região em virtude, entre outros fatores, do prolongamento da estrada de ferro Belém-Bragança. Os trabalhadores ocuparam o bairro do Reduto, motivados pelos baixos preços das moradias, pelo desinteresse do mercado imobiliário e pela proximidade com seus locais de trabalho.

O conglomerado industrial do Reduto passou, no entanto, por fortes crises nos anos seguintes, mormente quando da abertura da rodovia Bernardo Sayão (atual BR-010), promovida por políticas nacionais de integração do território amazônico, devido à dificuldade em competir em um mercado repleto de produtos vindos de outras regiões mais industrializadas e com elevado potencial de produção em larga 
escala a custos inferiores daqueles apresentados pelas fábricas da capital paraense. $\mathrm{O}$ enfraquecimento e o consequente fechamento das fábricas que ocupavam o bairro intensificaram a frequência de assentamentos precários.

Figura 1 - Aterramento da Doca do Reduto

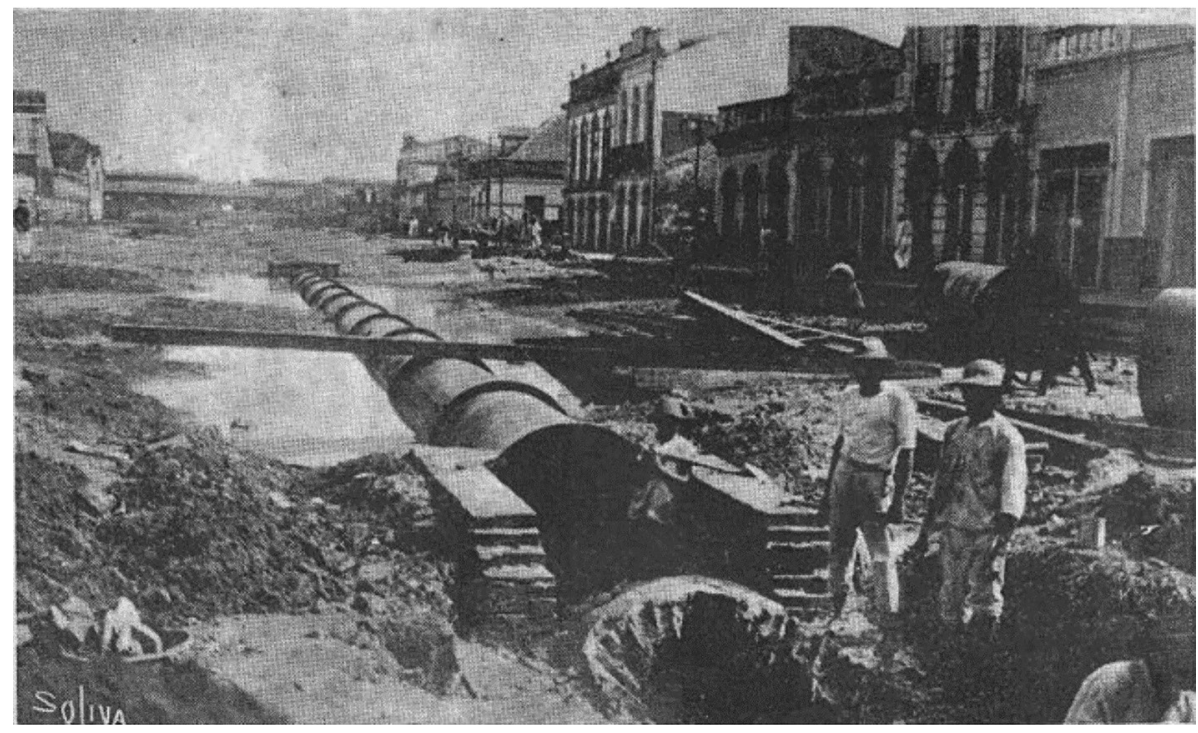

Fonte: FAUUFPA (2015).

Trindade Júnior (1999) ressalta que as áreas de várzea limítrofes ao município de Belém - como a do bairro do Reduto - funcionaram, entre 1960 e 1980, como focos políticos e de tensões sociais diversas, principalmente em relação à apropriação da terra urbana. Ainda conforme o autor, os conflitos ocorriam porque a fronteira urbano-imobiliária era interna aos limites da malha urbana, caracterizadas por uso não intensivo do mercado imobiliário. Como consequência, as baixadas eram predominantemente ocupadas por populações mais vulneráveis em relação ao acesso a serviços públicos primordiais, como saneamento básico, tornando-se núcleos de tensão, com manifestações da representatividade das demandas populares frente às autoridades políticas locais.

Concomitantemente, e com maior expressividade a partir de 1970, a intervenção do poder público - por meio de projetos de macrodrenagem e canalização do igarapé da região, e de política desenvolvida pelo Banco Nacional de Habitação (BNH) - desencadeou a migração forçada de famílias de baixa renda para o primeiro conjunto habitacional da COHAB em Belém: a valorização imobiliária dos terrenos do Reduto e a consequente intensificação da ocupação da área com edificações verticalizadas de luxo, além de serviços e 
usos comerciais específicos para atender ao novo público consumidor (ARAÚJO JÚNIOR; AZEVEDO, 2012) foram fatores responsáveis pela segregação social que delimitava a quem se destinavam as mudanças estruturais do bairro.

Tais fatores, associados a agentes externos, representados principalmente pela evolução do processo de reprodução social capitalista que, segundo Trindade Júnior (1999, p. 46), "pressupõe a existência da metrópole como condição à realização do padrão urbano-industrial, responsável por fazer do espaço uma força produtiva importante para o processo de reprodução do capital no território", estabeleceram a tendência de alteração dos padrões de ocupação daquela área de várzea, principalmente pela introdução de produtos imobiliários desenvolvidos para consumo da classe média, e a gentrificação das classes sociais C e D da baixada para o subúrbio, cada vez mais distantes do centro.

$\mathrm{Na}$ análise do bairro do Reduto, portanto, há diversos fatores políticos, econômicos e sociais ativos e preponderantes para as mudanças que ocorreram naquele bairro, sobretudo a partir de 1960, dentre os quais, pode-se destacar o surgimento de uma área de expansão da metrópole caracterizada pelo forte distanciamento da população em relação aos centros de bens e serviços e reforçando o processo de segregação espacial dentro do município, onde as classes mais abastadas ocupam o núcleo de oferecimento e acesso a bens e serviços e as famílias mais pobres são forçadas a migrar para áreas cada vez mais distantes do modo de vida e dos serviços básicos oferecidos à população. Desse modo, passam a se aproximar paulatinamente de modos de vida semelhantes àqueles observados em populações rurais, com distribuição precária de serviços de saneamento básico e de transporte público, quando existentes.

Além disso, as problemáticas associadas à dispersão da cidade e à migração de famílias vulneráveis e urbanas para regiões precárias de serviços e infraestrutura urbana adequada enfraquecem, conforme aponta Trindade Júnior (1999), as organizações políticas e sociais locais e a democratização da gestão do espaço público, além de institucionalizarem o sentimento de abandono e exclusão das populações periféricas pobres. O autor destaca que, desse modo, "prioriza-se o simples uso político do território e a consequente alienação do indivíduo com relação ao lugar e a sua inserção no processo de metropolização, em detrimento da consciência territorial" (TRINDADE JÚNIOR, 1999, p. 48).

A alteração dos padrões de uso e ocupação das áreas de várzea localizadas em áreas centrais do município, por sua vez, modifica ainda mais as interações dos indivíduos com os sistemas naturais remanescentes na cidade, como resultado de um processo de desenvolvimento paradoxal: são drasticamente alterados, ou 
mesmo extintos, os cursos d'água naturais para que se criem lagos artificiais em condomínios fechados; são removidas as coberturas vegetais para que se sinta a necessidade de desenvolver projetos de recuperação do espaço verde; a cidade e seus indivíduos perdem cada vez mais os componentes naturais tradicionais e o modelo de vida urbanizado torna-se cada vez mais sintético e impessoal.

A relação com a água dos rios e igarapés que cortavam a cidade também foi alterada substancialmente conforme o centro urbano evoluiu, aterrou alguns de seus cursos d'água e canalizou e modificou o traçado natural de outros cursos, por meio de projetos de infraestrutura urbana desenvolvidos pela gestão pública. A água, componente vital das antigas comunidades ribeirinhas para realização de suas atividades diárias, sendo também a principal via de circulação, distribuição e recebimento de mercadorias durante a ascensão industrial, notadamente no Reduto, além de mecanismo de acesso a outras comunidades também próximas dos cursos de rios, perdeu para a maior parte da população moderna esses aspectos que a compuseram como um dos principais atores do meio de vida amazônico, para se tornar um componente menos natural e mais distante do modo de vida das pessoas, como se pode inferir das abordagens realizadas por Trindade Júnior (2010, 2015).

Verificou-se, no entanto, que as alterações impostas por projetos de infraestrutura de canalização de rios e direcionamento de águas superficiais não corresponderam, ao longo das décadas subsequentes, às demandas de drenagem do bairro do Reduto e do município de Belém: frequentes desastres naturais associados a inundações e alagamentos, principalmente em áreas de baixada e trechos mais sensíveis da rede de drenagem, evidenciam falhas conceituais na nova relação dos indivíduos urbanos com a água. Tais fenômenos, por sua vez, ocorrem em resposta a diversos fatores, dentre os quais, pode-se destacar:

a) elevadas taxas pluviométricas municipais, que figuram entre as maiores do Brasil e chegam a $3000 \mathrm{~mm}$ anuais (SANTOS, 2017);

b) sistema de drenagem incompatível com a demanda de vazão, seja pelo mau dimensionamento, falta de manutenção preventiva ou acúmulo de lixo (TUCCI, 2002; FRAGOSO et al., 2016);

c) a interferência do regime de marés, que formam uma barragem hídrica que prejudica o escoamento (MARTINS, 2015);

d) a ocupação de áreas de várzea que poderiam contribuir para a percolação direta de águas superficiais. 
Santos (2017) aponta que, por estarem abaixo da cota altimétrica e relativamente mais próximos de cursos d'água, as baixadas são mais afetadas por alagamentos em períodos de maior volume pluviométrico, ou quando da cheia de rios. Além disso, Santos e Rocha (2015) afirmam que o avanço urbano representado pela retirada e substituição de camadas vegetadas permeáveis por coberturas impermeáveis corroboram para a ocorrência de desastres ambientais decorrentes do acúmulo de águas superficiais.

Estudos desenvolvidos por Sadeck, Souza e Silva (2012) e Pontes et al. (2017), por sua vez, apontaram diversos focos de alagamento no município de Belém em 2012 e 2017, observando que não houve avanços efetivos no combate a focos de alagamento entre os períodos analisados (Figura 2). A análise do levantamento realizado no estudo de Pontes et al. (2017) revelou ainda que, proporcionalmente à área total das redes hidrográficas, a bacia relativa aos canais da Doca e do Reduto está entre as três que mais sofrem com os alagamentos associados à ação conjunta de chuvas e cheias de maré.

Figura 2 - Pontos de alagamento identificados em estudos publicados nos anos de 2012 (a) e 2017 (b)

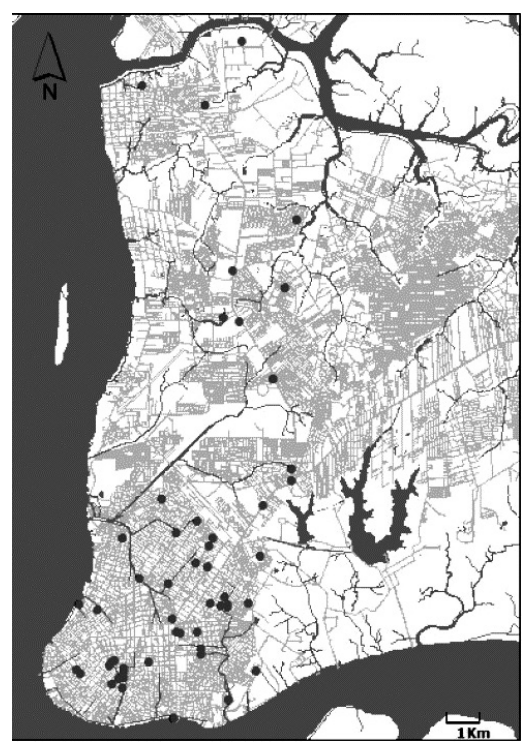

(a)

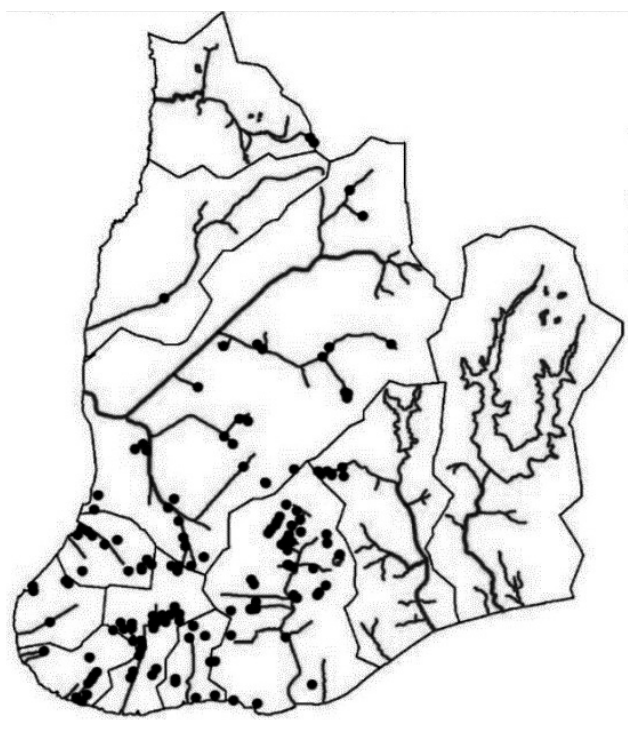

(b)

Fonte: Sadeck, Souza e Silva (2012) e Pontes et al. (2017).

Cruz (2018), a partir de análise urbanístico-ambiental dos padrões de uso e ocupação em bacias do município, aponta que a elevada valorização imobiliária da bacia do Reduto faz com que aquele território seja altamente impermeabilizado: as 
áreas permeáveis da bacia totalizam 2,06\% de toda a superfície, correspondendo majoritariamente a áreas internas de lotes, praças e à arborização de corredores viários, e apenas 1,1\% de declividade. Segundo Santos (2017), o percentual de permeabilidade aceitável para centros urbanos deveria figurar entre 20 e $25 \%$ de áreas intensamente impermeabilizadas, o que permite concluir que a bacia do Reduto apresenta apenas 10\% do percentual de permeabilidade desejável.

Cruz (2018) conclui então que a bacia apresenta padrão de escoamento deficitário, indicando como causas determinantes a elevada impermeabilização do solo e as baixas declividades, acrescentando-se ainda a esses fatores o fato de que o parcelamento de águas entre as bacias do Reduto e da Magalhães Barata direciona o escoamento de água para ambas, o que tem como consequência o agravamento dos picos de cheia.

Nota-se, portanto, que as problemáticas associadas a alagamentos e inundações no bairro do Reduto e em outras áreas de várzea no município demandam propostas de intervenção em drenagem urbana que sejam compatíveis com as causas associadas à problemática, em torno dos padrões de uso e ocupação do solo.

\section{USO DE TECNOLOGIAS COMPREENSIVAS PARA DRENAGEM}

Em uma abordagem global de enfrentamento das problemáticas de alagamentos nos centros urbanos, Tucci (2002) destaca a implementação de Planos Diretores de Águas Pluviais (PDAP) como recurso para gestão de sistemas de drenagem. As soluções devem contemplar, segundo o autor, propostas estruturais, que possam ser implementadas diretamente sobre os sistemas de macro e microdrenagem, e não estruturais, com medidas educacionais para a população e para a manutenção dos recursos hídricos.

Canholi (2005) afirma ainda que as medidas estruturais envolvem obras de engenharia, e podem ser intensivas - relacionadas ao escoamento de águas superficiais - ou extensivas - relacionadas mais comumente à adoção de sistemas de armazenamento e reservação temporária de águas pluviais, de modo a controlar e parcelar o volume escoado. As medidas não estruturais, segundo o autor, envolvem o controle de uso e ocupação de solos, mas também programas de educação ambiental voltados à correta utilização da água, além de medidas de previsão de inundações. A previsão de inundações tem função social de preparar a população e o município tanto para o remanejamento do tráfego e pessoas quanto para a garantia de que sejam mantidos serviços básicos e indispensáveis, sem causar maiores transtornos. 
As propostas de Tucci (2002) e Canholi (2005) exemplificam esforços e diretrizes para o enfrentamento de desastres ambientais de inundações, por meio de tecnologias e planos que possam atuar em concomitância com os sistemas de drenagem tradicionais. Historicamente, os mecanismos tradicionais de gestão de recursos hídricos e drenagem urbana envolvem propostas que visam ao escoamento acelerado de águas pluviais das áreas urbanas. Conforme Virgiliis (2009), a estruturação básica de sistemas tradicionais envolve, por exemplo, a captação de águas superficiais por bocas-de-lobo, o deságue até sistemas de macrodrenagem, como canais abertos e galerias, e o escoamento à jusante das bacias e sub-bacias urbanas. Sistemas tradicionais apresentam, conforme abordado ao longo do texto, altos picos de vazão e altas velocidades de escoamento nos condutos, justamente por possuírem como princípio o escoamento de águas superficiais no menor tempo possível.

Tais condicionantes, em situações extraordinárias de elevadas solicitações pluviométricas, ou quando os sistemas de drenagem foram mal dimensionados ou não foram submetidos a adequados processos de manutenção periódica, resultam em diversos focos de enchente, principalmente em zonas com cotas menos elevadas. Canholi (2005) propõe, desse modo, ações alternativas para evitar a elevação dos picos de cheia nas sub-bacias e bacias urbanas, destacando-se a manutenção do traçado natural do córrego original; a redução das declividades pela introdução de degraus ou manutenção das declividades naturais; e a adoção de revestimentos rugosos. Todas as soluções propostas apresentam como característica a redução da velocidade de translação do escoamento, aumento do tempo de concentração e redução dos picos de vazão nas sub-bacias afetadas.

No contexto de redução de picos de cheia e de vazão a jusante dos sistemas hídricos, surge a discussão em torno de infraestruturas compreensíveis e sustentáveis, compostas geralmente por infraestruturas verdes, sistemas naturais para armazenamento provisório e percolação de águas superficiais e pavimentos permeáveis. Canholi (2005) destaca a adoção de dispositivos de infiltração e percolação de águas superficiais, representada por jardins, telhados verdes e pavimentos porosos, que atuam no aumento do tempo de concentração e redução dos picos de vazão.

Os dispositivos, além de funcionarem como mecanismos de drenagem sustentáveis, por permitirem a redução da vazão a jusante nas sub-bacias às quais as águas superficiais serão direcionadas, e permitirem a percolação da água diretamente para o subsolo, podem ser utilizados como componentes paisagísticos do sistema urbano. 
Canholi (2005) aborda também a utilização de dispositivos de contenção a jusante, representada por sistemas de reservação incorporados à paisagem urbana, como reservatórios on-line - na mesma linha do trajeto de escoamento da bacia até o corpo receptor -, e off-line - paralelos ao trajeto de escoamento da bacia até o corpo receptor. Tais sistemas atuam também como dispositivos paisagísticos e de lazer da população.

Destaca-se, finalmente, que sistemas de drenagem compreensiva, além de atuarem como mecanismos mais limpos e sustentáveis, podem ser enquadrados como soluções inovadoras e eficientes, com potencial de armazenamento, purificação e reutilização de águas pluviais (DONG; GUO; ZENG, 2017; PENG et al., 2019; ZHONG; LENG; POON, 2018).

Cormier e Pellegrino (2008) apontam que a incorporação de dispositivos verdes à realidade urbana deve contemplar possibilidades de conexão com a realidade local. Segundo os autores, o único meio de tecnologias verdes progredirem em escala global é por meio do entendimento de que essas tecnologias devem ser continuamente adequadas às realidades regionais, de modo que respondam às demandas específicas das populações que serão responsáveis pelo sucesso de sua aplicação, utilização e manutenção.

Os autores destacam que as possibilidades de conexão da população com infraestruturas verdes remetem primeiramente à educação da comunidade de entorno, por meio do entendimento do funcionamento e do impacto de tais dispositivos sobre a realidade das pessoas. Depois, a conexão é representada pela identidade regional: o sucesso da adaptação de uma infraestrutura verde à determinada região depende intrinsecamente da compreensão das limitações e potencialidades locais em relação à tecnologia proposta.

Ratifica-se, portanto, que o sucesso de aplicação de tecnologias sustentáveis depende diretamente da relação que essas tecnologias terão com a realidade da comunidade local, tanto no que diz respeito ao entendimento que as pessoas terão do uso e à eficiência do dispositivo/sistema, quanto em relação à adaptação deste aos materiais locais e à paisagem da região.

Cormier e Pellegrino (2008) abordam, finalmente, a conexão por meio da arte, ou seja, pela incorporação das infraestruturas verdes em convergência com ações de artistas locais; a conexão por meio da ligação com o movimento moderno, de modo que os sistemas sustentáveis "conversem" com a arquitetura moderna; e a conexão por meio do encontro, ou seja, a incorporação das tecnologias verdes aos horários de lazer das pessoas, e a associação delas às coisas agradáveis que as pessoas imaginam quando pensam no sistema urbano. 
Rocha e Sattler (2017), por sua vez, defendem que a aceitação de tecnologias sustentáveis depende diretamente da percepção que o público tem da função e da incorporação da tecnologia ao sistema urbano. Os autores estabelecem que as tecnologias verdes devam ser projetadas de modo a tornar evidentes os benefícios advindos de sua aplicação, e com o cuidado de esclarecer procedimentos de uso e manutenção, evitando, desse modo, dúvidas e questionamentos.

Entre sistemas e dispositivos de drenagem sustentáveis, pode-se destacar o uso de pavimentos de concreto permeável, que funcionam tanto para infiltração direta de águas superficiais no subsolo quanto para reservação temporária de águas pluviais, de modo que reduzem a solicitação de vazão nos percursos d'água. A tecnologia apresenta grande potencial como alternativa sustentável para atuar como auxiliar aos sistemas tradicionais de drenagem de águas superficiais na região, com significativa redução da vazão. A utilização de pavimentos de concreto permeável potencializaria o percentual de coberturas com capacidade para drenar parte de águas superficiais, o que teria como consequência direta a menor solicitação dos sistemas de macro e microdrenagem em funcionamento, e minimizaria, por conseguinte, a incidência de desastres ambientais associados a focos de inundações e alagamentos.

\section{USO POTENCIAL DE COBERTURAS DRENANTES DE CONCRETO PERMEÁVEL PARA ESCOAMENTO DE ÁGUAS SUPERFICIAIS}

A tecnologia de coberturas drenantes de concreto permeável foi abordada inicialmente na Europa, ainda no século XIX, mas foi efetivamente incorporada como sistema de drenagem em residências e como componente de gestão para drenagem urbana somente a partir do fim da Segunda Guerra Mundial, quando da escassez de recursos financeiros e matéria-prima em diversos países devastados pela guerra. Desde então, notadamente na França, na Bélgica e na Escócia (AMERICAN CONCRETE INSTITUTE, 2011), tem sido utilizado como revestimento de vias e calçadas (SUZUKI; AZEVEDO; KABBACH JÚNIOR, 2013), além de funcionar como estrutura de apoio ao sistema de drenagem principal.

A regulamentação normativa norte-americana que regulamenta o dimensionamento, aplicação e manutenção de pavimentos de concreto permeável, ACI 522R-10 (AMERICAN CONCRETE INSTITUTE, 2011), apresenta diversas vantagens de pavimentos permeáveis sobre os pavimentos convencionais, impermeáveis, dentre as quais se pode destacar: o controle da poluição em águas 
pluviais; o controle de escoamento de águas pluviais; a capacidade de absorção e retenção de águas pluviais, que está diretamente relacionada à espessura das camadas, bem como ao percentual de vazios em cada camada; e a redução de derrapagem e reflexo em vias e autoestradas.

Chandrappa e Biligiri (2016), no entanto, afirmam que entre os empecilhos para ampla utilização de concretos permeáveis está na falta de padronização das propriedades específicas da tecnologia, e falta de especialistas no processo construtivo, que exige diversos cuidados. A American Concrete Institute (2011), por sua vez, apresenta potenciais desvantagens desse concreto especial, com destaque para:

- o uso de pavimentos de concreto permeável é limitado a áreas de tráfego leve; por se tratar de um material com elevado índice de porosidade, o concreto permeável apresenta resistência inferior a coberturas impermeáveis convencionais. É possível, no entanto, adaptar normas que estabelecem parâmetros de desempenho para pavimentos de concreto, como a regulamentação croata, General Technical Conditions for Roadwork (INSTITUT IGH, 2001), que define resistências mecânicas mínimas para aplicação de pavimentos de concreto permeável em vias de tráfego muito intenso;

- necessidade de controle tecnológico rigoroso; a tecnologia de concretos permeáveis demanda especial atenção com relação ao processo de cura e ao controle do concreto fresco;

- inviabilidade de uso da tecnologia para percolação de águas superficiais em solos argilosos, e risco de inutilização como cobertura em solos expansivos pela contaminação por finos ocasionada por poropressão negativa. Segundo Virgiliis (2009), o risco de ascensão de finos é maior em pavimentos submetidos a carregamentos lentos, como garagens e estacionamentos.

Vistos os potenciais ganhos ambientais provenientes da utilização dessa tecnologia, verifica-se a aplicabilidade de pavimentos permeáveis de concreto para funcionar como bacias de retenção e distribuição de águas pluviais, com a finalidade de reduzir os impactos ocasionados pela ação de chuvas intensas. O uso de camadas drenantes de concreto pode ser direcionado a calçadas, vias de tráfego leve, estacionamentos públicos e praças em geral, e possibilita redução da vazão total proporcional à área de cobertura impermeável substituída por cobertura permeável.

Em áreas de baixada, como o exemplo do Reduto, os pavimentos permeáveis podem ser aplicados em áreas a jusante da direção de escoamento 
de águas superficiais, de modo a reter temporariamente a água da chuva e, consequentemente, reduzir a vazão total e evitar a sobrecarga dos sistemas de coleta de água. Considerando-se ainda que o bairro apresenta apenas 10\% do percentual mínimo de coberturas permeáveis, destaca-se que tais pavimentos apresentam grande potencial de eficácia, visto serem sistemas que mimetizam coberturas vegetadas naturais com elevada capacidade para absorção e armazenamento de águas superficiais.

Sob essa perspectiva, considera-se que $25 \%$ da área total de influência da bacia do Reduto sejam compostos por vias asfaltadas e impermeáveis (DIAS; LUZ, 2017), verifica-se que cada $10 \%$ de substituição de vias de asfalto por camadas drenantes de concreto permeável possibilitaria em torno de 3\% de incremento de espaços permeáveis totais à área abrangida pela bacia do Reduto. Ressalta-se a potencial aplicação da tecnologia em vias para tráfego de pedestres, estacionamentos, garagens, parques e praças.

Observa-se, portanto, que a tecnologia apresenta grande potencial como alternativa sustentável para atuar como auxiliar aos sistemas tradicionais de drenagem de águas superficiais na região, com significativa redução da vazão. A utilização de pavimentos de concreto permeável potencializaria o percentual de coberturas com capacidade para drenar parte das águas superficiais, o que teria como consequência direta a menor solicitação dos sistemas de macro e microdrenagem em funcionamento, e minimizaria, por conseguinte, a incidência de desastres ambientais associados a focos de inundações e alagamentos.

\section{CONSIDERAÇÕES FINAIS}

O presente texto teve como objetivo discutir as relações de ocupação e uso do solo no bairro do Reduto, em Belém do Pará, bem como processos de substituição de camadas vegetadas naturais por coberturas impermeáveis. Foram avaliados os agentes motivadores e os impactos sociais e ambientais das intervenções humanas sobre os sistemas de drenagem naturais. Após a discussão inicial a respeito da progressão histórica de ocupação do bairro, foram apresentadas, como propostas para apaziguar os impactos do avanço da urbanização e impermeabilização de solos sobre o escoamento de águas superficiais, sistemas de drenagem compreensivos, que tem como objetivo reduzir os impactos das ações humanas sobre os sistemas ambientais e mimetizar condições de solos naturais em regiões já ocupadas.

Destacou-se, desse modo, o uso de coberturas drenantes de concreto permeável à jusante das áreas afetadas por alagamentos na área de discussão, 
que possam funcionar como bacias de armazenamento e redistribuição de águas superficiais. Ressalta-se, desse modo, os benefícios potenciais provenientes da aplicação de tal tecnologia, como a redução de vazão superficial, armazenamento e filtragem de águas pluviais.

Conclui-se, a partir da discussão proposta, que o uso de coberturas drenantes de concreto, em substituição às coberturas impermeáveis convencionais, tem grande potencial para atuar como sistema auxiliar para drenagem urbana, não somente na área analisada no estudo, mas em diversos trechos do município de Belém, visto a capacidade de reduzir o escoamento superficial onde for aplicado, além de funcionar como bacia de reservação de águas pluviais.

\section{REFERÊNCIAS}

AMERICAN CONCRETE INSTITUTE. ACI 522R-10: report on pervious concrete. Michigan: ACI, 2011.

ARAÚJO JÚNIOR, A. C. R. A.; AZEVEDO, A. K. A. Formação da cidade de Belém (PA): área central e seu papel histórico e geográfico. Espaço Aberto, Rio de Janeiro, v. 2, n. 2, p. 151-168, 2012.

CANHOLI, A. P. Drenagem urbana e controle de enchentes. São Paulo: Oficina de Textos, 2005. 305 p.

CHANDRAPPA, A. K.; BILIGIRI, K. P. Pervious concrete as a sustainable pavement material - Research findigns and future prospects: A state-of-the-art review. Construction and Building Materials, [S. l.], v. 111, p. 262-274, may 2016. CORMIER, N. S.; PELLEGRINO, P. R. M. Infraestrutura verde: uma estratégia paisagística para a água urbana. Paisagem Ambiente, São Paulo, n. 25, p. 125 142, 2008.

CORRÊA, R. L. Estudos sobre a rede urbana. 2. ed. Rio de Janeiro: Bertrand Brasil, 2006. 332 p.

COSTA, M. C. L.; LOBO, M. A. A. Esse rio é minha avenida: transformações socioespaciais, elitização e exclusão em Belém (PA). In: TOBIAS, M. S. G.; LIMA, A. C. M. Urbanização \& meio ambiente. Belém: Editora UNAMA, 2012. p. 141-165.

CRUZ, C. C. C. S. Uso e ocupação do solo nas bacias hidrográficas da região metropolitana de Belém: uma análise urbanístico-ambiental. 2018. Dissertação (Mestrado em Arquitetura e Urbanismo) - Programa de Pós-Graduação em Arquitetura e Urbanismo, Universidade Federal do Pará, Belém, 2018. 
DIAS, R. P.; LUZ, L. M. Análise multitemporal do uso e ocupação do solo da bacia hidrográfica urbana de Armas-Reduto, Belém-PA. In: SIMPÓSIO BRASILEIRO DE SENSORIAMENTO REMOTO, 18., 2017, Santos-SP. Anais [...]. Santos SP: INPE, 2017. p. 1893-1900.

DONG, X.; GUO, H.; ZENG, S. Enhancing future resilience in urban drainage system: green versus grey infrastructure. Water Research, [S. l.], v. 124, n. 2, p. 80-89, 2017.

FAUUFPA. Doca do Reduto - aterramento: 1910(?). FAU - Laboratório Virtual - ITEC/UFPA, Belém, 27 mar. 2015. Disponível em: https:/ / fauufpa. org $/ 2015 / 03 / 27 /$ doca-do-reduto-\%E2\%80\%95-aterramento-1910/. Acesso em: 10 jan. 2019.

FRAGOSO, G. A.; SILVA, F. P.; SILVA, J. C. C.; ALVES, A. F.; CARVALHO, B. G. P. Diagnóstico do sistema de drenagem urbana da cidade de Belém, Pará: uma análise dos principais bairros da cidade. In: ENCONTRO NACIONAL DE ESTUDANTES DE ENGENHARIA AMBIENTAL, 14, 2016, Brasília. Anais [...]. São Paulo: Blucher, 2016. p. 1263 - 1269.

INSTITUT GH. General technical conditions for roadworks. Zagreb: IGH, 2001.

MARTINS, V. C. D. Avaliação de sistemas de prevenção e contenção de inundações em bacia de drenagem urbana. 2015. Dissertação (Mestrado em Engenharia Civil) - Programa de Pós-Graduação em Engenharia Civil, Universidade Federal do Pará, Belém, 2015.

PENG, Z.; JINYAN, K.; WENBIN, P.; XIN, Z.; YUANBIN, C. Effects of low-impact development on urban rainfall runoff under different rainfall characteristics. Polish Journal of Environmental Studies, [S. l.], v. 28, n. 2, p. 771-783, 2019.

PENTEADO, A. R. Belém do Pará: estudo de geografia urbana. Belém: EDUFPA,1968. 448 p. v. 2.

PONTE, J. P. X.; BRANDÃO, A. J. N. Urbanistic subsidies for a Metropolitan Drainage Plan, Belém, Brazil. In: WORLD CONGRESS ON ENGINEERING, 1., 2014, London. Proceedings [...]. London: WCE, 2014. p. 156-160.

PONTES, M. L. C.; LIMA, A. M. M.; SILVA JÚNIOR, J. A.; SADECK, C. C. A. Dinâmica das áreas de várzea do município de Belém/PA e a influência da precipitação pluviométrica na formação de pontos alagamentos. Caderno de Geografia, Belo Horizonte, v. 27, n. 49, p. 285-303, 2017. 
ROCHA, C. G.; SATTLER, M. A. Improving acceptance of more sustainable technologies: Exploratory Study in Brazil. Journal of Urban Planning and Development, [S. l.], v. 143(2), p. 05016015-1 - 05016015-6, 2017.

SADECK, L. W. R.; SOUZA, A. A. A.; SILVA, L. C. T. Mapeamento das zonas de risco às inundações no município de Belém-PA. In: ENCONTRO NACIONAL DA ANPPAS, 6., 2012, Belém. Anais [...]. Belém: UFPA, 2012. p. 1-11.

SANTOS, C. M .S. O uso da drenagem como Método de Avaliação de Desempenho da Ocupação Urbana: uma reflexão sobre a avenida Augusto Montenegro. 2017. Dissertação (Mestrado em Arquitetura e Urbanismo) Programa de Pós-Graduação em Arquitetura e Urbanismo, Universidade Federal do Pará, Belém, 2017.

SANTOS, F. A. A.; ROCHA, E. J. P. Alagamento e inundação em áreas urbanas. Estudo de caso: cidade de Belém. Revista Geoamazônia, Belém, v. 2, n. 1, p. 33-55, 2015.

SUZUKI C. Y.; AZEVEDO, A. M.; KABBACH JÚNIOR, F. A. Drenagem subsuperficial de pavimentos - conceitos e dimensionamento. São Paulo: Oficina de Textos, 2013. 240 p.

TRINDADE JÚNIOR, S-C. C. Assentamentos urbanos e metropolização na Amazônia brasileira: o caso de Belém. In: ENCUENTRO DOS GEOGRAFOS DA AMERICA LATINA, 7., 1999, San Juan. Anales [...]. San Juan: Universidad de Porto Rico, 1999. p. 35-45.

TRINDADE JÚNIOR, S-C. C. Assentamentos urbanos e metropolização na Amazônia brasileira: o caso de Belém. GEOUSP: Espaço e Tempo (Online), n.4, p.39-52, 1999. Disponível em: https://www.revistas.usp.br/geousp/article/ view/123318/119664. Acesso em: 08 maio 2020.

TRINDADE JÚNIOR, S-C. C. Cidades na floresta: os "grandes objetos" como expressões do meio técnico-científico informacional no espaço amazônico. Revista do Instituto de Estudos Brasileiros, São Paulo, n. 51, p. 113-137, mar./set. 2010 .

TRINDADE JÚNIOR, S-C. C. Pensando a modernização do território e a urbanização difusa na Amazônia. Mercator, Fortaleza, v. 14, n. 4, p. 93-106, 2015.

TUCCI C. E. M. Gerenciamento da drenagem urbana. Revista Brasileira de Recursos Hídricos, [S. l.], v. 7, n. 1, p. 5-27, jan./mar. 2002. 


\section{VIRGILIIS, A. L. C. D. Procedimento de projeto e execução de pavimentos} permeáveis visando retenção e amortecimento de picos de cheia. 2009. Dissertação (Mestrado em Engenharia de Transportes) - Departamento de Engenharia de Transportes, Escola Politécnica da Universidade de São Paulo, Universidade de São Paulo, São Paulo, 2009. Disponível em: http://www.teses. usp.br/teses/disponiveis/3/3138/tde-08092010-122549/pt-br.php. Acesso em: 10 jan. 2019.

ZHONG, R.; LENG, Z.; POON, C. Research and application of pervious concrete as a sustainable pavement material: a state-of-the-art and state-of-thepractice review. Construction and Building Materials, [S. l.], v. 183, n. 5, p. 44-53, 2018. 